\title{
Solar System Exploration Augmented by
} Lunar and Outer Planet Resource Utilization: Historical Perspectives and Future Possibilities

Bryan Palaszewski

Glenn Research Center, Cleveland, Ohio 


\section{NASA STI Program . . . in Profile}

Since its founding, NASA has been dedicated to the advancement of aeronautics and space science. The NASA Scientific and Technical Information (STI) program plays a key part in helping NASA maintain this important role.

The NASA STI Program operates under the auspices of the Agency Chief Information Officer. It collects, organizes, provides for archiving, and disseminates NASA's STI. The NASA STI program provides access to the NASA Aeronautics and Space Database and its public interface, the NASA Technical Reports Server, thus providing one of the largest collections of aeronautical and space science STI in the world. Results are published in both non-NASA channels and by NASA in the NASA STI Report Series, which includes the following report types:

- TECHNICAL PUBLICATION. Reports of completed research or a major significant phase of research that present the results of NASA programs and include extensive data or theoretical analysis. Includes compilations of significant scientific and technical data and information deemed to be of continuing reference value. NASA counterpart of peer-reviewed formal professional papers but has less stringent limitations on manuscript length and extent of graphic presentations.

- TECHNICAL MEMORANDUM. Scientific and technical findings that are preliminary or of specialized interest, e.g., quick release reports, working papers, and bibliographies that contain minimal annotation. Does not contain extensive analysis.

- CONTRACTOR REPORT. Scientific and technical findings by NASA-sponsored contractors and grantees.
- CONFERENCE PUBLICATION. Collected papers from scientific and technical conferences, symposia, seminars, or other meetings sponsored or cosponsored by NASA.

- SPECIAL PUBLICATION. Scientific, technical, or historical information from NASA programs, projects, and missions, often concerned with subjects having substantial public interest.

- TECHNICAL TRANSLATION. Englishlanguage translations of foreign scientific and technical material pertinent to NASA's mission.

Specialized services also include creating custom thesauri, building customized databases, organizing and publishing research results.

For more information about the NASA STI program, see the following:

- Access the NASA STI program home page at http://www.sti.nasa.gov

- E-mail your question to help@sti.nasa.gov

- Fax your question to the NASA STI Information Desk at 443-757-5803

- Phone the NASA STI Information Desk at 443-757-5802

- Write to: STI Information Desk NASA Center for AeroSpace Information 7115 Standard Drive Hanover, MD 21076-1320 
Solar System Exploration Augmented by Lunar and Outer Planet Resource Utilization: Historical Perspectives and Future Possibilities

Bryan Palaszewski

Glenn Research Center, Cleveland, Ohio

Prepared for

SciTech 2014

sponsored by the American Institute of Aeronautics and Astronautics

National Harbor, Maryland, January 13-17, 2014

National Aeronautics and

Space Administration

Glenn Research Center

Cleveland, Ohio 44135 
Level of Review: This material has been technically reviewed by technical management.

Available from

NASA Center for Aerospace Information 7115 Standard Drive

Hanover, MD 21076-1320
National Technical Information Service 5301 Shawnee Road Alexandria, VA 22312

Available electronically at http://www.sti.nasa.gov 


\title{
Solar System Exploration Augmented by Lunar and Outer Planet Resource Utilization: Historical Perspectives and Future Possibilities
}

\author{
Bryan Palaszewski \\ National Aeronautics and Space Administration \\ Glenn Research Center \\ Cleveland, Ohio 44135
}

\begin{abstract}
Establishing a lunar presence and creating an industrial capability on the Moon may lead to important new discoveries for all of human kind. Historical studies of lunar exploration, in-situ resource utilization (ISRU) and industrialization all point to the vast resources on the Moon and its links to future human and robotic exploration. In the historical work, a broad range of technological innovations are described and analyzed. These studies depict program planning for future human missions throughout the solar system, lunar launched nuclear rockets, and future human settlements on the Moon, respectively. Updated analyses based on the visions presented are presented. While advanced propulsion systems were proposed in these historical studies, further investigation of nuclear options using high power nuclear thermal propulsion, nuclear surface power, as well as advanced chemical propulsion can significantly enhance these scenarios.

Robotic and human outer planet exploration options are described in many detailed and extensive studies. Nuclear propulsion options for fast trips to the outer planets are discussed. To refuel such vehicles, atmospheric mining in the outer solar system has also been investigated as a means of fuel production for high energy propulsion and power. Fusion fuels such as helium $3(3 \mathrm{He})$ and hydrogen $\left(\mathrm{H}_{2}\right)$ can be wrested from the atmospheres of Uranus and Neptune and either returned to Earth or used in-situ for energy production. Helium 3 and $\mathrm{H}_{2}$ (deuterium, etc.) were the primary gases of interest with hydrogen being the primary propellant for nuclear thermal solid core and gas core rocket-based atmospheric flight. A series of analyses have investigated resource capturing aspects of atmospheric mining in the outer solar system. These analyses included the gas capturing rate, storage options, and different methods of direct use of the captured gases. While capturing $3 \mathrm{He}$, large amounts of hydrogen and $4 \mathrm{He}$ are produced. With these two additional gases, the potential for fueling small and large fleets of additional exploration and exploitation vehicles exists.
\end{abstract}

\section{Nomenclature}

$\begin{array}{ll}3 \mathrm{He} & \text { helium } 3 \\ 4 \mathrm{He} & \text { helium (or helium } 4) \\ \mathrm{AMOSS} & \text { atmospheric mining in the outer solar system } \\ \mathrm{CC} & \text { closed cycle } \\ \mathrm{CH}_{4} & \text { methane } \\ \Delta \mathrm{V} & \text { change in velocity }(\mathrm{km} / \mathrm{s}) \\ \mathrm{GCNR} & \text { gas core nuclear rocket } \\ \mathrm{GCR} & \text { Galactic Cosmic Rays } \\ \mathrm{GTOW} & \text { Gross Takeoff Weight } \\ \mathrm{H}_{2} & \text { hydrogen } \\ \mathrm{He} & \text { helium } 4 \\ \text { ISRU } & \text { in situ resource utilization } \\ \text { Isp } & \text { specific impulse (s) }\end{array}$




$\begin{array}{ll}\text { K } & \text { Kelvin } \\ \text { kT } & \text { kilotons of explosive power } \\ \text { kWe } & \text { kilowatts of electric power } \\ \text { LEO } & \text { low Earth orbit } \\ \text { M dry, stage } & \text { stage dry mass }(\mathrm{kg}) \\ \mathrm{M} \text {, dry coefficient } & \text { stage dry mass coefficient, B } \\ \mathrm{M} \mathrm{p} & \text { propellant mass }(\mathrm{kg}) \\ \mathrm{MT} & \text { metric tons } \\ \text { MWe } & \text { megawatt electric (power level) } \\ \text { NEP } & \text { Nuclear Electric Propulsion } \\ \text { NPP } & \text { Nuclear Pulse Propulsion } \\ \text { NTP } & \text { Nuclear Thermal Propulsion } \\ \text { NTR } & \text { Nuclear Thermal Rocket } \\ \text { OC } & \text { open cycle } \\ \mathrm{O}_{2} & \text { oxygen } \\ \text { PPB } & \text { parts per billion } \\ \text { UAV } & \text { Uninhabited Aerial Vehicle }\end{array}$

\subsection{Introduction}

Human and robotic missions have been planned for targets throughout the solar system. Both types of missions can benefit greatly from the resources available from the planets and/or their moons. These benefits include water on many of the outer planet moons and large asteroids. With this water, $\mathrm{O}_{2} / \mathrm{H}_{2}$ rocket propulsion systems can be fueled, breathing $\mathrm{O}_{2}$ can be extracted, and other life support functions (cooling fluids, etc.) can be facilitated. In addition, the atmospheres of many planets have ready reserves of gases for propellant production. Carbon dioxide on Mars can be separated into $\mathrm{O}_{2}$ and carbon monoxide or $\mathrm{CH}_{4}$. The outer planets offer enormous amounts of energetic gases such as $\mathrm{H}_{2}, 3 \mathrm{He}, \mathrm{CH}_{4}$, and ammonia. By using these in-situ resources, robotic precursor missions can double or triple their payloads to the surface and return double or triple the samples from the solar system targets. Without insitu resource utilization (ISRU), solar system exploration will be exceedingly limited. For future large scale human missions, the possibilities of ISRU for of human exploration and finally settlement offer the best opportunities for sustainability and success.

\subsection{Human Exploration Options}

In the 1950s, 1960s, 1970s, and 1980s, ambitious robotic and human mission were planned, spanning from Mercury to the outermost reaches of the solar system (Refs. 1 to 10). While investments in robotic missions have continued, human exploration of the solar system has awaited new invigorating steps. While lunar and Mars missions are in the early step-wise planning stages, many cost barriers have prevented their implementation. Future human missions to other destinations such as Mercury and Saturn will also require long-term investments. Currently, Mercury and Saturn have robotic missions returning invaluable data on those planets and their environs (Refs. 11 and 12). These data have provided insights that will ensure the success of future missions. With its proximity to the Sun, Mercury has extremely high temperatures and requires special high heat flux considerations for long-term human visits or bases. In contrast, temperatures at Saturn and its moons require designs for cryogenic environments. The possibilities for ISRU may allow more effective robotic missions and human visits to these planetary targets. 


\subsection{Mercury}

Mercury is the closest planet to the Sun; ranging from a perihelion of 46 million $\mathrm{km}$ to an aphelion of nearly 70 million $\mathrm{km}$. The high temperature, high heat flux environment at Mercury and the tenuous surface emanations of several major chemical species (sodium, etc.) surrounding it will likely pose challenges to long term human visits. Permanently shadowed craters offer a valuable niche for longer term human visits and planetary bases. Such craters offer cryogenic temperatures while the sun facing surface is at a temperature of 590 to $725 \mathrm{~K}$. The north polar regions of Mercury have been identified as a likely location for such permanently shadowed craters (Refs. 11, 12, and 13). Water ice is also likely to be in these craters, further aiding and assisting any human explorations. Short exploratory missions can be accomplished with hopping ascent-descent vehicles from the base at the shadowed crater.

Figure 1 shows the locations of the shadowed craters (Ref. 12). Figure 2 depicts the temperatures that would exist in and near the craters (Ref. 13). The crater could accommodate a small base or at least an initial landing site. The lander's temperature could stay within the nominal operating temperatures of traditional spacecraft. The temperature distribution in the crater would allow construction of the base at the warmer side of the crater and then the frozen volatiles would be extracted with cryogenic mining machines.

\subsection{Saturn and Its Moons}

Saturn is one of the outer planets. Its orbit has a perihelion 1,352.6 million $\mathrm{km}$ and an aphelion 1,514.50 million $\mathrm{km}$. An extensive series of flybys of the Saturnian moons have been conducted by the Cassini spacecraft. During these flybys, cameras and instruments capture and data on the moons' composition, atmosphere and cloud cover (on the moon Titan), volcanos, plumes, rotation, and gravity.

Titan is the largest moon of Saturn. Its intriguing nature includes a nitrogen and $\mathrm{CH}_{4}$ atmosphere and a subsurface ocean (Ref. 14). Recent flybys of the Cassini spacecraft have shown direct visual evidence of the northern lakes which are likely composed of $\mathrm{CH}_{4}$. Based on measurements and theories of the evolution of Titan, a large ocean of water and ammonia may exist below the icy surface. Large lakes in the North Polar regions have been seen on Titan's surface, and they are likely composed of liquid $\mathrm{CH}_{4}$. Figure 3 shows the possible nature of Titan's interior, surface, and atmosphere. While $\mathrm{CH}_{4}$ can be used as an effective rocket propellant, its nitrogen could be used in cold gas propulsion or electric propulsion (resistojet, arcjet or magneto-plasma-dynamic (MPD) thrusters).

\subsection{Enceladus}

The moon Enceladus is producing a large plume of water that is escaping into space. Speculation on the production of that water varies. The South Polar region has several hot spots (a cryogenic, volcanic area), known as the tiger stripes, matching the location of the plume of water exiting Enceladus (Ref. 15).

In-situ resources from the Titan water ocean can be used for rocket propellants. Access to the ocean may only require drilling a short (or km long) distance into the icy crust. At Enceladus, the water plume may be captured, or the ocean of reservoir feeding the plume will be tapped. Capturing this water may prove difficult, however, and additional research is needed to find the best manner of fluid capturing.

\section{$2.4 \quad$ Asteroids}

An excellent additional target may be Ceres, the largest asteroid in our solar system. Ceres may provide substantial water from its water ice and the potential ocean below the ice (Ref. 16). As with Enceladus, drilling through many $\mathrm{km}$ of ice may be required and finding sufficiently deep crevasses will no doubt be useful in easing the drilling requirements. 


\subsection{Mission Studies}

\subsection{Mercury Missions}

A human round trip mission to Mercury was assessed. The mission $\Delta \mathrm{V}$ values for the round trip Mercury missions were derived from References 17 to 20 . The highest $\Delta \mathrm{V}$ case was selected from this data: an Earth departure $\Delta \mathrm{V}$ of $5.2 \mathrm{~km} / \mathrm{s}$, a Mercury arrival $\Delta \mathrm{V}$ of $10.9 \mathrm{~km} / \mathrm{s}$ and a Mercury departure $\Delta \mathrm{V}$ of $8.7 \mathrm{~km} / \mathrm{s}$ (Ref. 17). Each $\Delta \mathrm{V}$ was delivered by a separate single stage; thus a three stage vehicle is used. At Earth, a capsule enters the atmosphere to return the crew directly to Earth. The capsule's mass is $4,350 \mathrm{~kg}$ (Ref. 17). The round trip time is 585 days with a 40 day stay time at Mercury (Ref. 15). In this case, the vehicle does not land on Mercury. The LEO masses of both chemical propulsion and nuclear thermal propulsion vehicles were estimated. Figure 4 compares the LEO masses for two types of chemical propulsion systems and two nuclear thermal propulsion (NTP) systems. The interplanetary chemical propulsion systems used tankage dry mass coefficients of 3 and 5 percent of the total propellant mass in the tankage. In many cases, these dry masses may be deemed to be optimistically low; however, they allow some relative comparison of the chemical propulsion and the nuclear mission cases.

The NTP vehicles dry mass was 15 percent of the propellant mass (Table 1). In current NTP designs, an Isp of $900 \mathrm{sec}$ is nominally used (Refs. 23 and 24). Somewhat lower Isp values were used for these missions: 800 and $850 \mathrm{sec}$, respectively. These lower Isp values were assumed given the high heat flux environment of Mercury and the degraded Isp values would reflect the added propellant used for propellant cooling and/or refrigeration. The chemical propulsion systems required between 17,150 and $27,000 \mathrm{MT}$ to accomplish the mission. The NTP vehicles required approximately an order of magnitude less mass in LEO: 1,700 to 2,300 MT.

TABLE 1.-SPACE VEHICLE DRY MASS COEFFICIENT AND ROCKET ENGINE SPECIFIC IMPULSE (Isp)

\begin{tabular}{|l|c|c|}
\hline \multicolumn{1}{|c|}{ Technology } & $\begin{array}{c}\text { Isp } \\
(\mathrm{sec})\end{array}$ & $\begin{array}{c}\text { M, dry coefficient } \\
(\mathrm{kg} / \mathrm{kg} \mathrm{M}, \mathrm{p})\end{array}$ \\
\hline Chemical-1 & 450 & 0.03 \\
\hline Chemical-2 & 450 & 0.05 \\
\hline Chemical lander & 480 & 0.20 \\
\hline NTP-1 & 800 & 0.15 \\
\hline NTP-2 & 850 & 0.15 \\
\hline
\end{tabular}

Based on Reference 21, the stage and lander mass was estimated with the following mass scaling equation:

$$
\mathrm{M} \text { dry,stage }(\mathrm{kg})=\mathrm{M}, \text { dry coefficient } * \mathrm{M} \mathrm{p}(\mathrm{kg})
$$

A Mercury landing vehicle mass was also estimated. The one-way $\Delta \mathrm{V}$ for the lander was $3.5 \mathrm{~km} / \mathrm{s}$ (Ref. 22). The ascent $\Delta \mathrm{V}$ was also $3.5 \mathrm{~km} / \mathrm{s}$. These $\Delta \mathrm{V}$ values accommodate approximately 19 percent for gravity losses for each maneuver; this gravity loss $\Delta \mathrm{V}$ is added to the orbital velocity for a $100 \mathrm{~km}$ orbit which is $2.945 \mathrm{~km} / \mathrm{s}$. The lander Isp was $480 \mathrm{sec}$. The higher Isp was chosen for the lander as the engine used a higher engine expansion ratio that the interplanetary transfer vehicle (Ref. 21). The smaller engine size would allow a higher expansion ratio, given the typical volume constraints for space vehicles. The dry mass coefficient was 20 percent of the total propellant load. While the Mercury missions will likely require more aggressive thermal control (propellant shielding, cooling, etc.), that thermal control system mass is accommodated in the payload mass of the vehicle. The payload delivered to the surface was 10 MT. Figure 5 compares the mass in LEO of a one-way lander and a round trip lander. The masses were 140 MT for the round trip lander and 27 MT for the one way lander. Thus, using ISRU on the surface of Mercury to replenish the lander's propellant would allow a savings of 113 MT on this mission. Additional analyses are needed to investigate the mass reductions for the interplanetary transfer vehicle to carry the 
lander to Mercury. Another option would be to carry five landers to Mercury rather than carry simply one lander; many more permanently shadowed craters could then be visited on one mission. The interplanetary vehicle carrying the five landers could be sent on a lower energy trajectory than the human flights, thus saving additional mass launched into LEO in the overall Mercury architecture.

Additional summary data on mission design is summarized in Reference 20. Figure 6 provides map of the one-way $\Delta \mathrm{V}$ and trip time for a wide range of planetary targets (Ref. 20). Fast missions to Jupiter and Mercury are possible with $\Delta \mathrm{V}$ values of 80 to $100 \mathrm{~km} / \mathrm{s}$. Nuclear propulsion systems may someday allow such ambitious missions and if augmented by ISRU, such mission will be within our technological reach

\subsection{Atmospheric Mining in the Outer Solar System (AMOSS)}

Atmospheric mining in the outer solar system can be a powerful ISRU tool in extracting fuels from the outer planets and allow fast human and robotic exploration of the solar system. Preliminary designs of aerospacecraft with gas core rocket nuclear engines for mining the outer planets were developed (Refs. 23 and 24). Helium 3, a nuclear fusion fuel, would be extracted from the atmosphere and stored for final delivery to orbital assets. Analyses showed that gas core nuclear rocket (GCNR) engines can reduce the mass of such aerospacecraft mining vehicles very significantly: from 72 to 80 percent reduction over nuclear thermal propulsion (NTP) solid core powered aerospacecraft mining vehicles. While this mass reduction is important in reducing the mass of the overall mining system, the complexity of a fissioning plasma gas core rocket is much higher than the more traditional solid core NTP engines. Additional analyses were conducted to calculate the capture rates of $3 \mathrm{He}_{2}$ and $4 \mathrm{He}$ during the mining process. Very large masses of $\mathrm{H}_{2}$ and $4 \mathrm{He}$ are produced every day during the often lengthy process (multi-day) of $3 \mathrm{He}$ capture and gas separation. Figure 7 shows the mass of $\mathrm{H}_{2}$ needed for the gas core rocket and the potentially excess $\mathrm{H}_{2}$ captured every day (Ref. 23). Typically, these very large (excess) additional fuel masses can dwarf the requirements needed for $\mathrm{H}_{2}$ captured for ascent to orbit. Thus, the potential for fueling small and large fleets of additional exploration and exploitation vehicles exists. Aerial vehicle designs can take on many configurations. Additional aerospacecraft or other uninhabited aerial vehicles (UAVs), or balloons, rockets, etc., could fly through the outer planet atmospheres, for global weather observations, localized storm or other disturbance investigations, wind speed measurements, polar observations, etc. Deep-diving aircraft (built with the strength to withstand many atmospheres of pressure) powered by the excess $\mathrm{H}_{2}$ or $4 \mathrm{He}$ may be designed to probe the higher density regions of the gas giants.

Based on these past analyses, there will likely be several possible future avenues for effective use of the gases of the outer planets for exciting and scientifically important atmospheric exploration missions. The analyses focused on Uranus and Neptune, as these planets offer vast reservoirs of fuels that are more readily accessible than those from Jupiter and Saturn (as these latter planets require lower energies needed to attain orbit and present less danger from powerful atmospheric lightning) and, with the advent of nuclear fusion propulsion, may offer us the best option for fast interplanetary travel and the first practical interstellar flight.

\subsection{Nuclear Underground Explosions}

Based on recent measurements and simulations of the lunar radiation environment, it appears that long term occupancy of the lunar surface may be detrimental to human beings. In addition to the long term exposure to natural radiation sources (galactic cosmic rays, solar flares, etc.), there is additional scattered radiation on the lunar surface (Ref. 25). Based on these most recent measurements and the past work in lunar bases, it seems reasonable to assess living and working in underground facilities on the Moon. Using small of large nuclear devices on the Moon may provide an option for creating a series of large habitable underground spaces. Project Plowshare in the 1960s (Refs. 26 to 33) addressed some of the issues with using nuclear devices to complete large scale redirection of rivers, building canals, and many other massive civil engineering projects. 
Past Earth based nuclear weapons testing often was done underground due to the Nuclear Test Ban Treaty of 1963 . The tests often left sizable craters on the surface. When a nuclear device is sufficiently deeply buried, the explosive force can be completely contained underground (Ref. 26, Figure 8). The blast vaporizes some of the surrounding rocky material which then expands and creates an underground cavity, as shown in Figure 8. In most cases the weight of overhead rock soon crumbles the roof of the void chamber and a vertical column (or chimney) is created by the successively falling loose rocky layers. The material in the chimney undergoes compaction after the roof collapse but the initial amount of void space created by the blast just after detonation is distributed in this broken rocky debris. Small robotic mining systems could be used to manage the debris. Based on historical data, such a space can also be spherical if the blast size is sufficiently small. After the radiation has fallen to acceptable levels, people could potentially create comfortable living spaces.

In Reference 7, this technique was proposed for not only living spaces, but for large scale ISRU. Nuclear explosions would be used to melt and vaporize lunar regolith. Figure 9 illustrates four different processes using nuclear detonations (Ref. 7). There are two chambers: one for the nuclear explosion, and one for the reaction product capturing. This processing would essentially chemically reacting $\mathrm{O}_{2}, \mathrm{H}_{2}$, or other species. The processes range from creating $\mathrm{O}_{2}$ and metal oxides to producing water and metal carbides. From Reference 7:

"A nuclear charge of one kiloton, detonated underground, fractures approximately 80,000 cubic meters or 330,000 tons of lunar rock, containing 130,000 MT of oxygen. At least 1\%, or 33,000 $M T$, of the rock is fully evaporated. The silicon and metals condense quickly. But, since they are in an essentially pure oxygen atmosphere, they also reoxidize vigorously. Estimating, very conservatively, that only 20 to $30 \%$ of the liberated oxygen can be extracted and stored, this means that through the underground detonation of a one-kiloton nuclear charge, of a systems mass of a few hundred pounds, 6,000 to 10,000 MT (Earth weight) of oxygen can be provided. '”

Certainly, extensive processing will require maintenance of the nearly spherical cavities and effective pumping schemes to introduce the gases into the underground chambers for the planned reactions. However the rates of production may be high enough to warrant the use of nuclear detonations.

\subsection{Lunar Slide Lander}

The lunar slide lander uses friction between a descending tubular spacecraft and a prepared runway of lunar regolith. The operations of the slide lander are in eight phases (Ref. 8):

1. Elliptical orbit descent.

2. Perilune maneuver (pre-landing retro-thrust).

3. Approach to touchdown (cut in supporting (vertical) thrust at the end of Phase 3).

4. Touchdown with harenodynamic tail brake. A positive angle of attack is maintained by the supporting thrust.

5. Initiation of main drag phase. Touchdown of harenodynamic side brakes.

6. Main drag slide phase with supporting thrust.

7. Main drag slide phase without supporting thrust.

8. Final braking by means of additional braking devices, or brief retro-thrust, for a controlled stop.

The slide lander was an attempt to reduce the total propellant load required for lunar landings. While the approach velocity of the lander is over $1,500 \mathrm{~m} / \mathrm{s}$, the long slide process may reduce the total $\Delta \mathrm{V}$ required to 200 to $450 \mathrm{~m} / \mathrm{s}$. This is in comparison to the $2,000 \mathrm{~m} / \mathrm{s}$ typically used for lunar landing (Ref. 34). Precise landing control is required and the length of the landing strip area is approximately $80 \mathrm{~km}$. Additional studies have identified that the dust from the initial phase of the slide landing may attain an attitude of 1,300 of $\mathrm{km}$ (Ref. 8). Thus, while the landing methods saves much precious 
propellant, the implications of the flying dust on other lunar surface and orbital operations must be addressed.

\subsection{Nuclear Pulse Propulsion}

Using nuclear devices for propulsion is another product of the creativity of the 1960s engineering and physics community (Refs. 35 to 38). The nuclear pulse propulsion (NPP) systems were seriously considered for fast transportation throughout the solar system. Small nuclear devices would be detonated behind a large piloted spacecraft, and the detonation would power the vehicle. Many 1000's of such pulses were required for outer planet missions. The predicted specific impulse for these vehicles is between 1,800 and 6,000 sec (Ref. 34). The NPP vehicles were considered a logical precursor to the pulsed fusion propulsion systems, noted in many of the AMOSS studies (where $3 \mathrm{He}$ and deuterium nuclear fuels are mined from the gas giant planets).

Nuclear pulse propulsion freighters were conceived to return 3,000 MT payloads of raw or processed materials from many targets in the solar system. Figure 10 shows the mission energies, the transportation and propellant costs for such a large nuclear freighter (Ref. 8). These analyses noted NPP Isp values from 6,000 to $10,000 \mathrm{sec}$ (Ref. 8). To support such operations perhaps nuclear bomblet factories would be constructed all through the solar system. While constructing large nuclear facilities on every location of human exploration may be optimistic, certainly several locations for extended exploration should be chosen for such nuclear sites. Smaller nuclear facilities will be a first step, using smaller reactors.

\subsection{Observations}

While human missions to Mercury and Saturn and all of the other planets will be challenging and require long-term investments, the results from these missions and their development will no doubt have great influences on our economy and improve our technological prowess.

Krafft Ehricke envisioned a poly-global civilization, with branches of humanity in many far flung places in our solar system (Ref. 1). His vision was uniquely expressed in Reference 36. Here is a short excerpt from that work:

"Our helionauts, as these men who fly our large interplanetary vehicles call themselves in this era of continuing specialization, have covered the solar system from the sun scorched shores of Mercury to the icy cliffs of the Saturn moon, Titan. They have crossed, and some have died doing so, the vast asteroid belt between Mars and Jupiter and have passed through the heads of comets. Owing to the pioneer spirit, the courage and the knowledge of our helionauts and of those engineers, scientists, and technicians behind them, astrophysicists today work in a solar physics station on Mercury; biologists experiment on Mars, backed by a well-supplied research and supply station on the Mars moon, Phobos; planetologists have landed on Venus; and teams of scientists right now study what have turned out to be the two most fascinating of our solar system, Jupiter and Saturn, from research stations on Callisto and Titan. ',

These helionaut flights would be the precursors of human outposts and then colonies all through the solar system. Multiple systems employing planetary ISRU could enable all of these ideas and concepts. Krafft Ehricke envisioned an entire extensive lunar economy, producing power, finished and raw materials, and NPP launching bases for extensive exploration of the solar system. The poly-global civilization was considered a natural expansion of the human experience, pioneering new frontiers and using technology in the best interests of all humanity. 


\subsection{Concluding Remarks}

A wide range of space exploration technologies have been assessed in many studies from the 1960s to today. In an optimistic future, lunar exploration will lead to base construction and, with time, lead to extensive lunar industrial investments. There are a wide range of potential lunar industries: raw materials processing, $\mathrm{O}_{2}$ and other propellant production, nuclear and solar power, etc. These industries may lead to small scale devices and large scale products: from microchip production to the creation of completely new space vehicles. Many of the suggested industries were related to power production to be transmitted to Earth or other attractive locales in the Earth-Moon space.

The need for safe lunar bases may lead to creating underground structures. If extended visits or permanent colonization of the Moon is needed, humans will require protection from long term radiation exposure as well as intense solar events such as coronal mass ejection, galactic cosmic rays, and lunar surface scattering of radiation. Using explosive forming of underground cavities may lead to an attractive lunar base or colony. Additional industrialization options include nuclear explosion based processing of raw lunar materials. Large scale mining of lunar raw materials and gas production and capture from underground nuclear processing of the in-situ materials has been suggested.

Missions to several planetary targets in the solar system were considered: Mercury, Saturn, and its moons, Titan and Enceladus, as well as the asteroid, Ceres. The LEO masses were estimated for the Mercury mission scenarios. Lander (ascent/descent) vehicles for Mercury were also assessed. The mass of the lander vehicles for Mercury was 140.1 MT for the round trip lander and 27 MT for a one-way deliver lander to the surface. Each carried a 10 MT payload. With ISRU, five landers could be delivered to Mercury's surface rather than one. The LEO masses for the human round trip Mercury missions was reduced by an order of magnitude, from 27,000 MT to 2,300 or 1,700 MT, using nuclear thermal propulsion over chemical $\mathrm{O}_{2} / \mathrm{H}_{2}$ propulsion systems. Using ISRU at Mercury would likely further benefit a range of such missions.

Atmospheric mining in the outer solar system can produce nuclear fusion fuels such as $3 \mathrm{He}$ which are rare on Earth. In addition, while extracting the small fraction of $3 \mathrm{He}$ in the gas giant atmospheres, each day enormous amounts of $\mathrm{H}_{2}$ and $\mathrm{He}$ are produced. These amounts can far outstrip the needed for propellants to return the mining aerospacecraft to orbit. These additional $\mathrm{H}_{2}$ and $\mathrm{He}$ gases can augment many additional UAVs and probes for extended exploration of those planets' atmospheres and local environs.

Solar system exploration using in-situ resource utilization can allow higher quality missions with much large data return. Larger more effective research and sample return missions are possible. Faster missions are possible by using the local planetary resources to return to Earth. By not carrying all of the return propellants, larger propellant loads in LEO can enable shorter mission flight times. Truly impressive interplanetary missions can be within our reach with focused investments. 


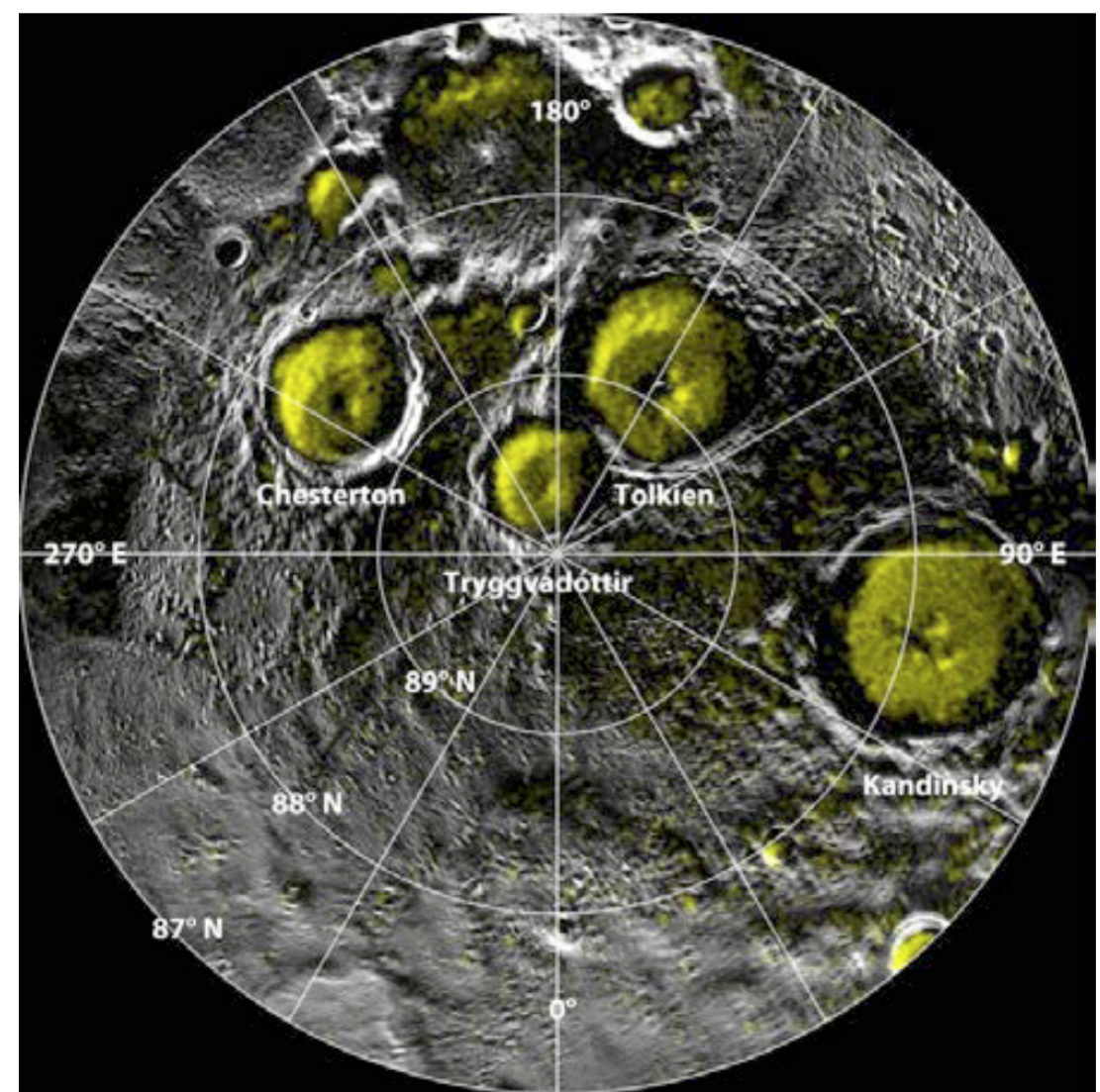

Figure 1.-Permanently shadowed craters in Mercury's North Polar region (Ref. 12, used with permission).

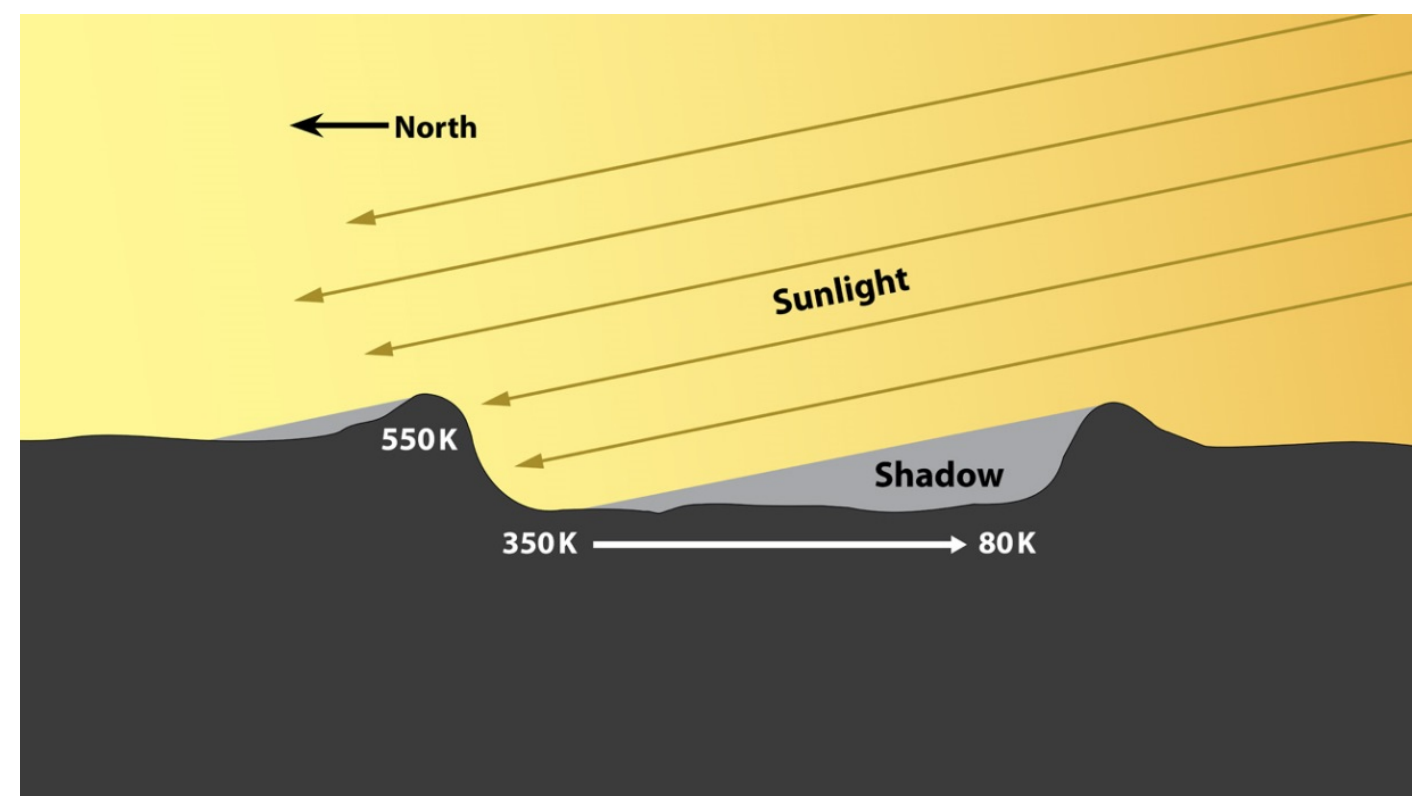

Figure 2.-Temperature ranges outside and inside permanently shadowed craters (Ref. 13). 


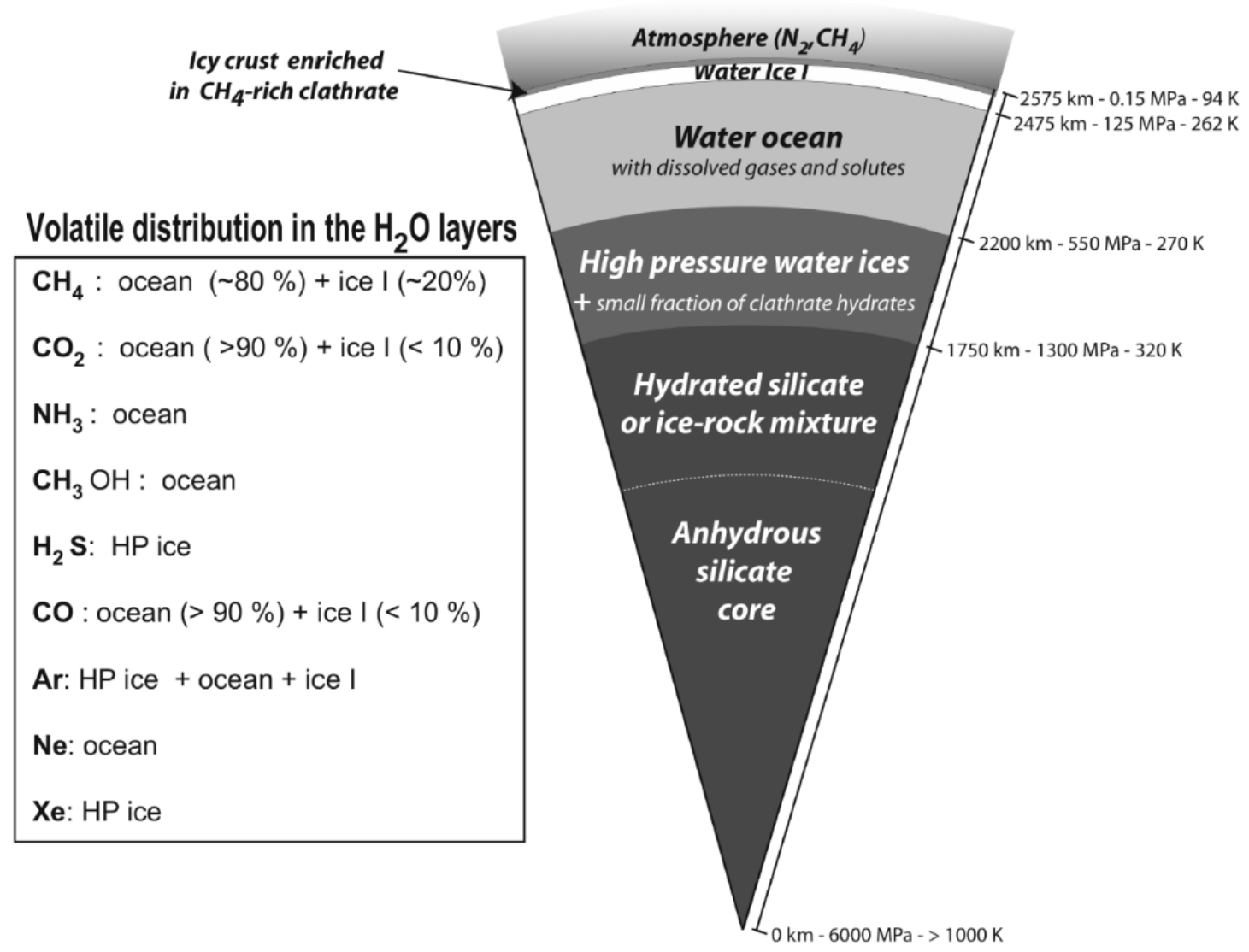

Figure 3.-Possible present day cross section of Titan (Ref. 14, reprinted with the permission of Cambridge University Press.).

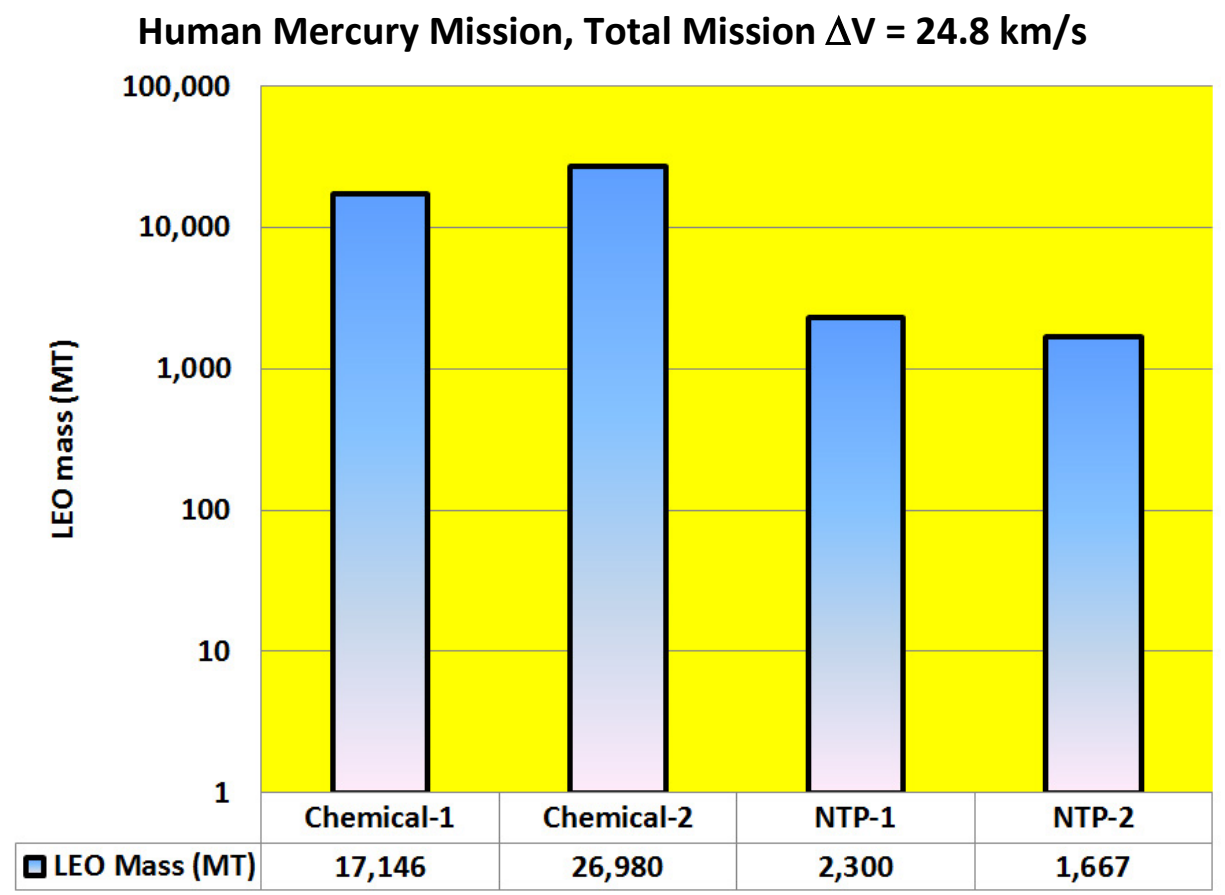

Figure 4.- - LEO masses of human round trip missions to Mercury. 


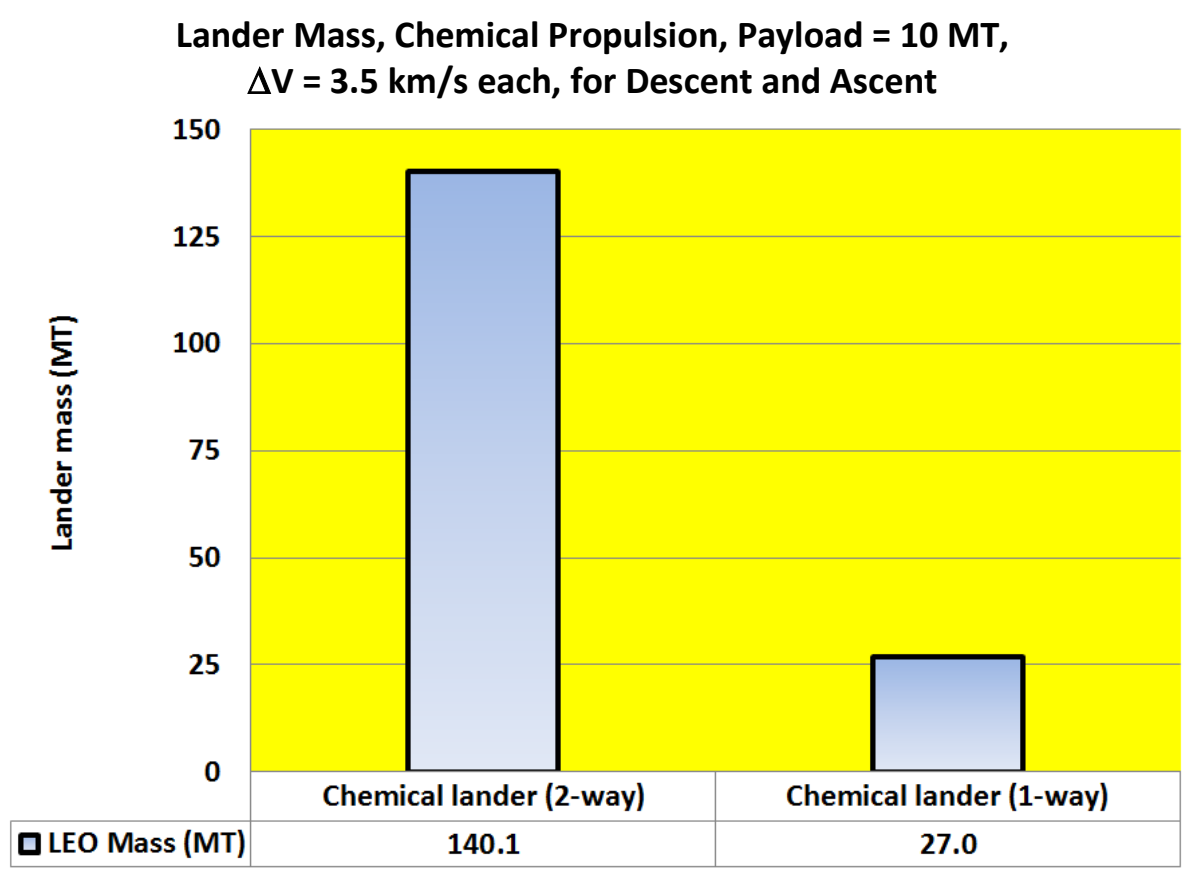

Figure 5.-LEO masses of lander vehicles for missions to Mercury.

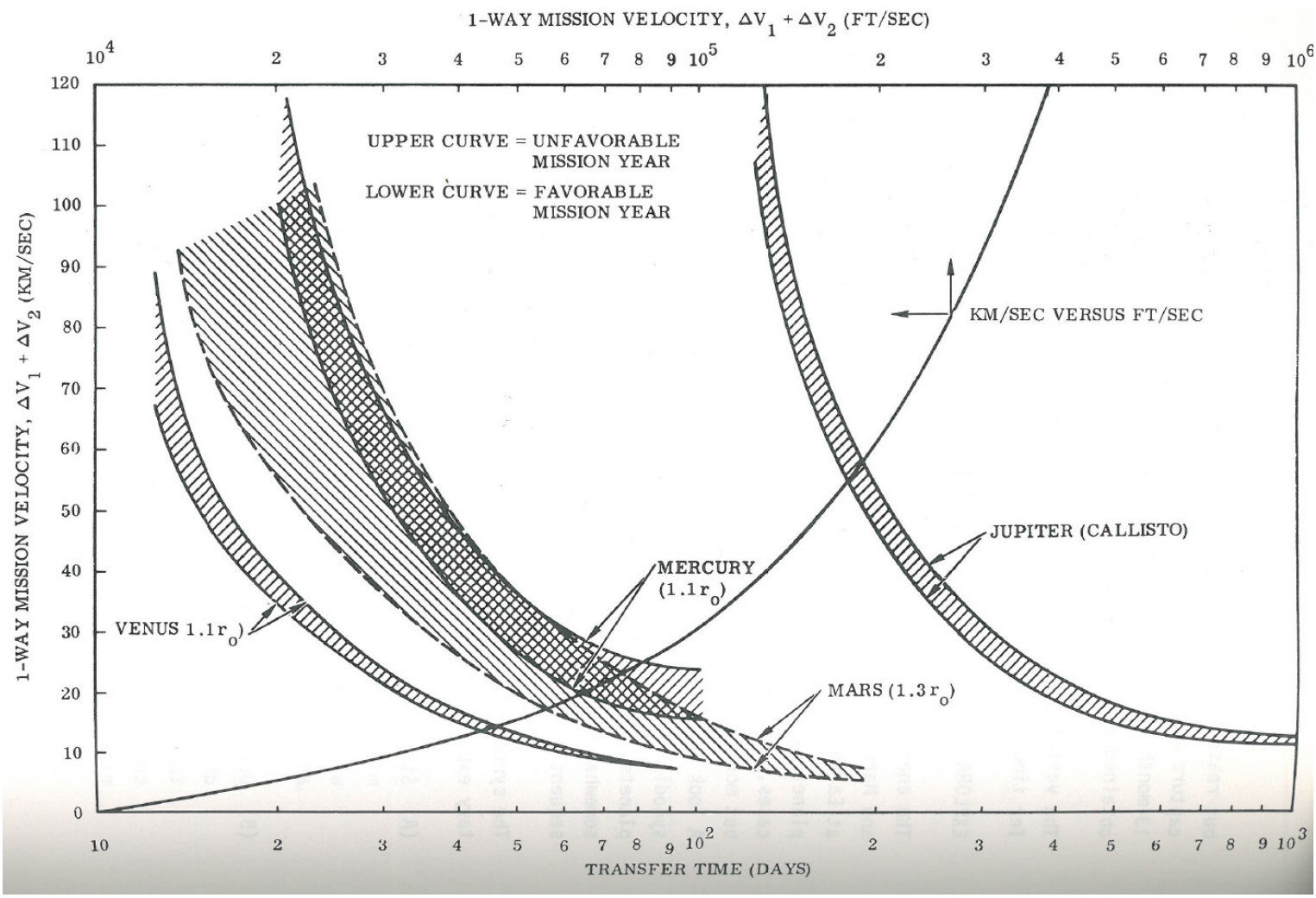

Figure 6. - One-way interplanetary mission $\Delta \mathrm{V}$ versus trip time for various targets (Ref. 20). ${ }^{1}$

${ }^{1}$ This figure was originally presented at the American Astronautical Society (AAS) $16^{\text {th }}$ Annual Meeting, Anaheim, CA, and was originally published in the AAS publication "Space Shuttles and Interplanetary Flight," ed. L. Larmore and R.L. Gervais, Vol. 28, Advances in Astronautical Sciences, 1970, p. 364 (Copyright (C) 1970 by American Astronautical Society Publications Office, Web Site http://www.univelt.com). 


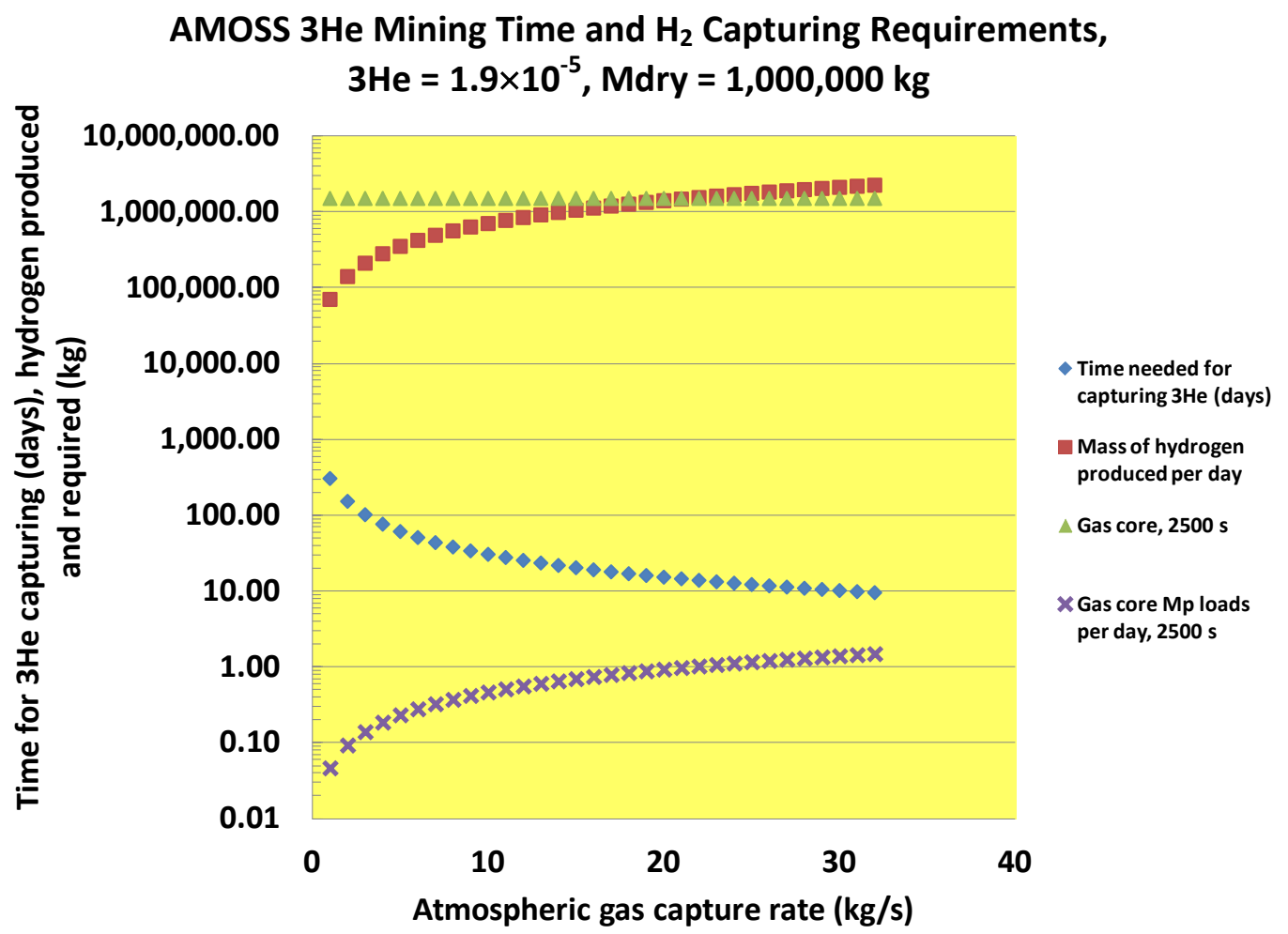

Figure 7.-Helium 3 mining time and $\mathrm{H}_{2}$ capture (mass per day) versus atmospheric gas capture rate for Neptune AMOSS (Ref. 23).

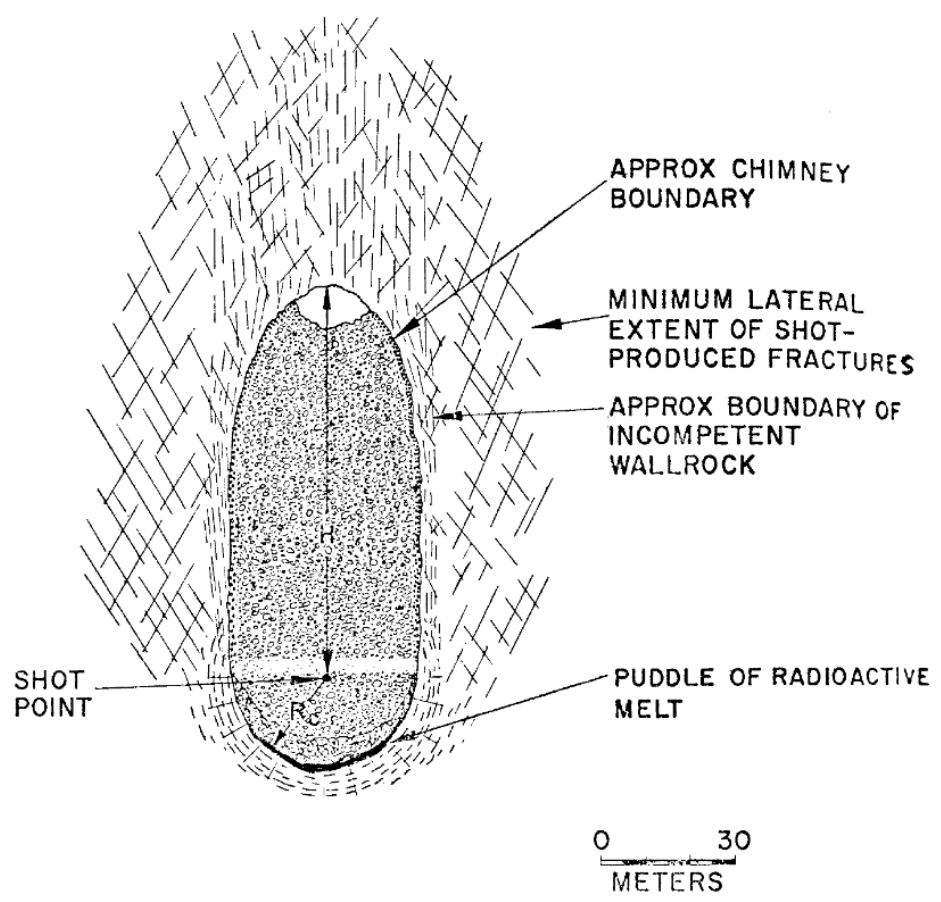

Figure 8.- Schematic cross section of a hard rock medium after contained nuclear explosion (Ref. 26). 


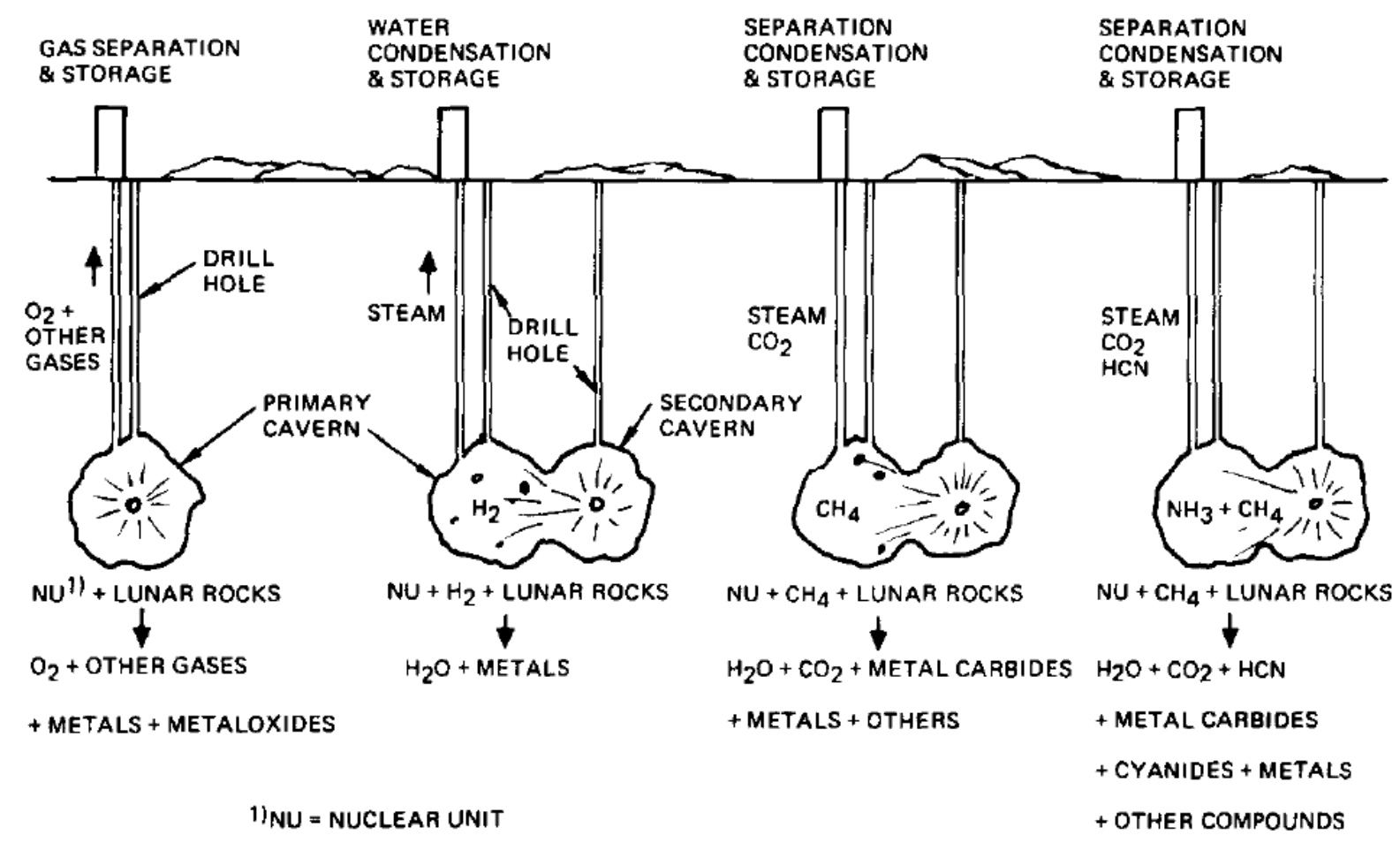

Figure 9.-Nuclear detonation processing (Ref. 7).

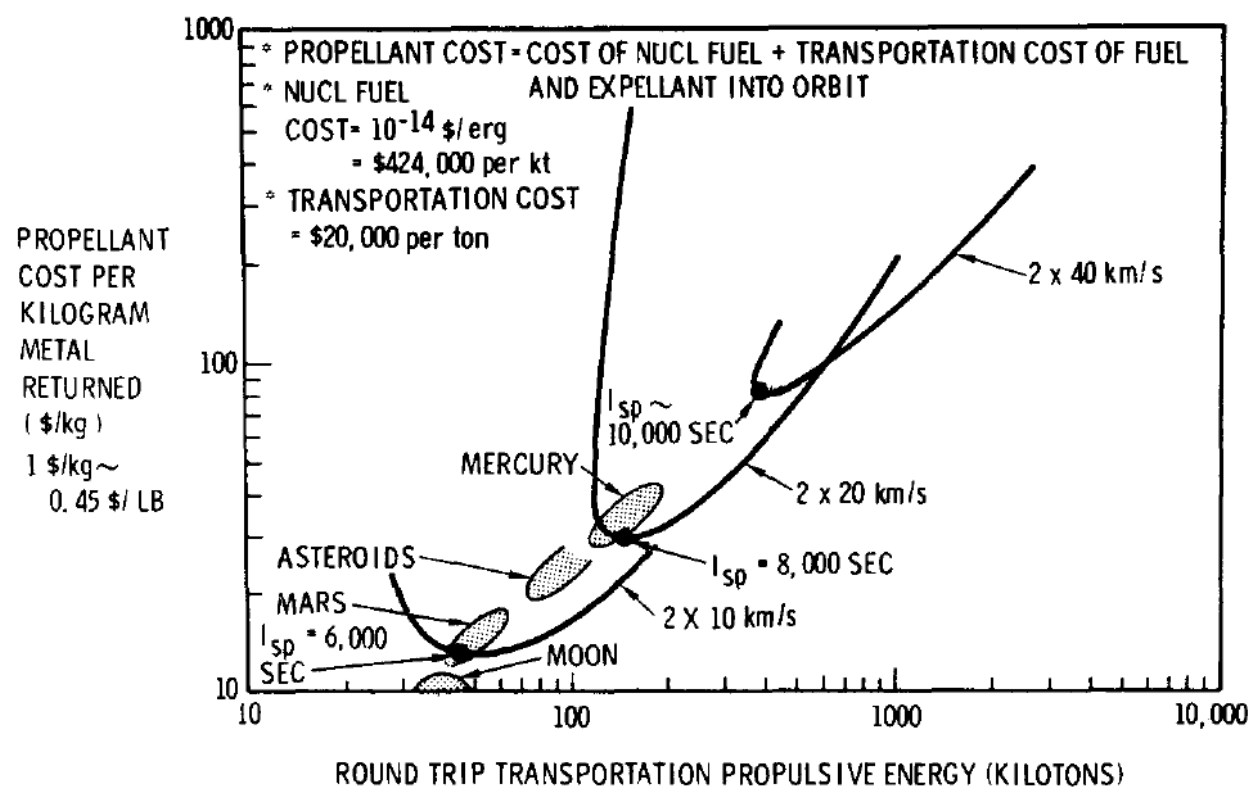

Figure 10.-Nuclear pulse propulsion freighter propellant costs for 3.000 MT payload (Ref. 7). 



\section{Appendix A.-Comparison of Several Trajectory Modes for Manned and Unmanned Missions to Mercury 1980 to 2000 (AIAA 67-28)}

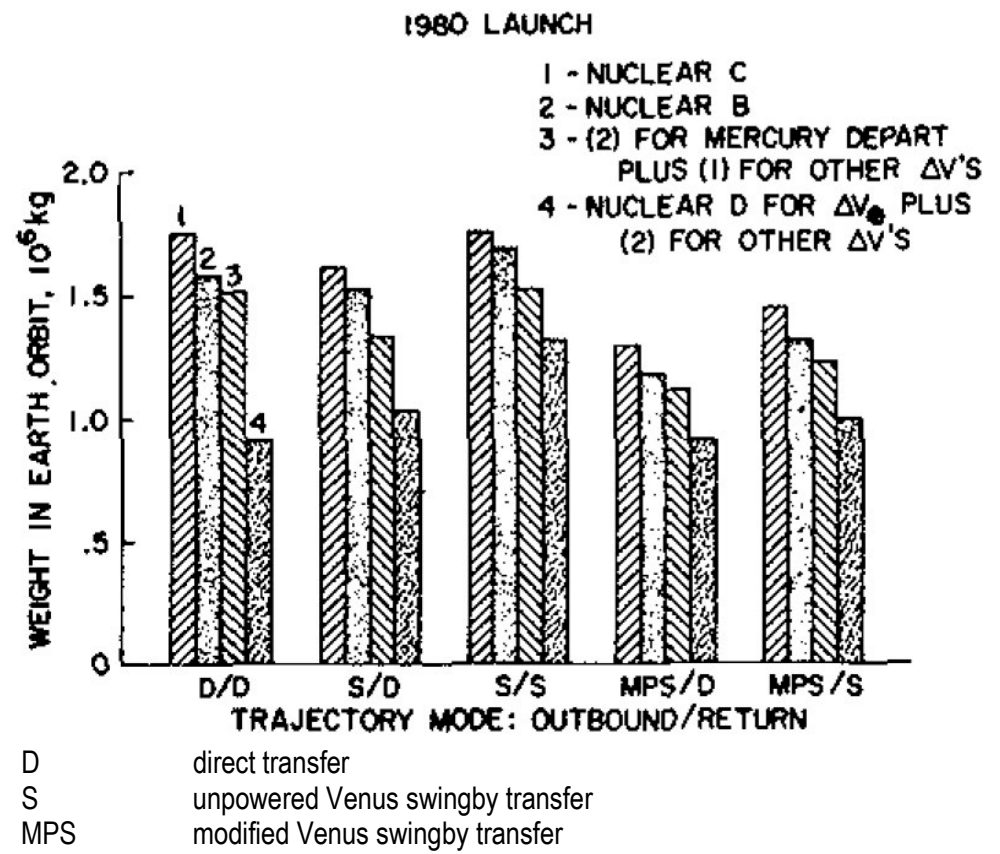

Figure A.1.-Comparison of Earth orbit weight requirements; manned Mercury stopover mission (Figure 10 in Ref. 17).

Propulsion and performance data.

- Engine characteristics

\begin{tabular}{|c|c|c|c|c|}
\hline Eng ine & $I_{\mathrm{sp}}, \mathrm{sec}$ & Weight $\left(\mathrm{w}_{E}\right), \mathrm{kg}$ & $\mathrm{T} / \mathrm{W}$ & Propellant \\
\hline Chemical & 450 & Vartable & 80 & $\mathrm{O}_{2} / \mathrm{H}_{2}$ \\
\hline Nuclear A & 800 & 1,600 & 2.9 & $\mathrm{H}_{2}$ \\
\hline Nuclear B & 850 & 8,000 & 4.4 & $\mathrm{H}_{2}$ \\
\hline Nuclear C & 850 & 17,000 & 6.2 & $\mathrm{H}_{2}$ \\
\hline Nuclear D & 2,000 & 115,000 & 2.0 & $\mathrm{H}_{2}$ \\
\hline
\end{tabular}


TABLE A.1.-MINIMUM $\Delta$ V REQUIREMENT; MANNED MERCURY STOPOVER MISSION (TABLE 1 IN REF. 17)

(a) Trajectory mode comparison: 1980 launch

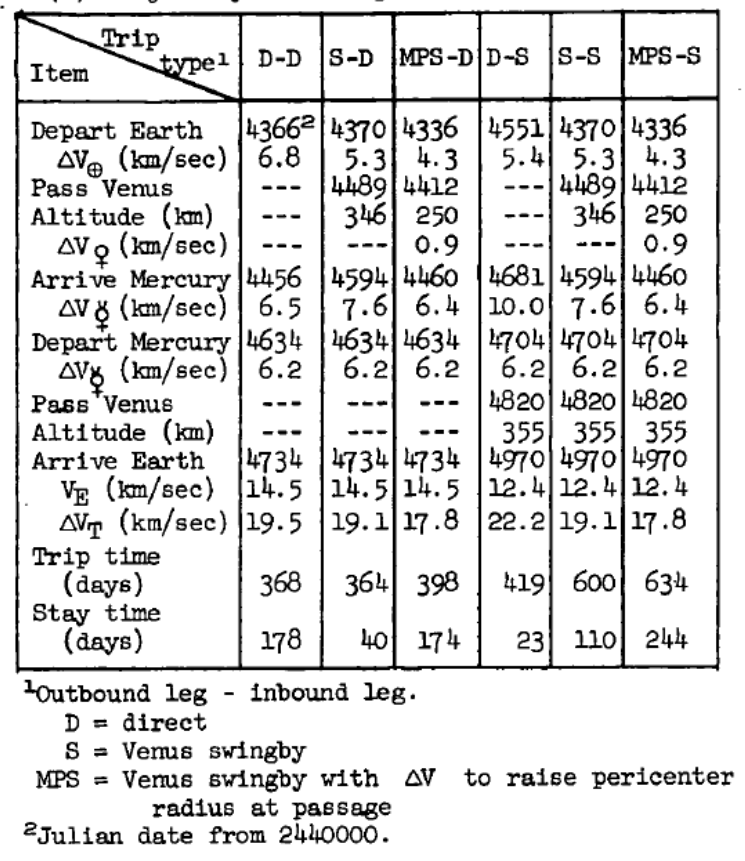

(b) Trajectory mode compar1son: 1983 launch

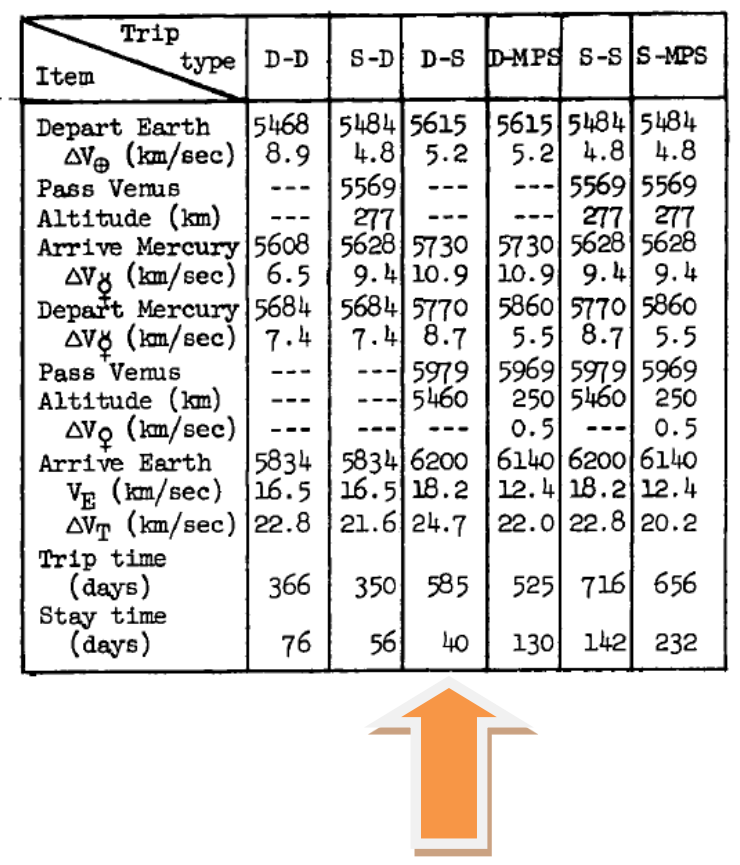

Selected mission design

TABLE A.2.-MINIMUM $\Delta$ V TRAJECTORY CHARACTERISTICS-MANNED MERCURY STOPOVER MISSION (TABLE 2(C) IN REF. 17)

\begin{tabular}{|c|c|c|c|c|c|c|c|c|c|}
\hline $\begin{array}{c}\text { Launch } \\
\text { year }\end{array}$ & $\begin{array}{c}\text { Earth } \\
\text { departure date } \\
\text { (Julian) }\end{array}$ & $\begin{array}{c}\Delta \mathrm{V}, \\
\text { Earth } \\
(\mathrm{km} / \mathrm{s})\end{array}$ & $\begin{array}{c}\text { Venus } \\
\text { swingby date } \\
(\mathrm{J})\end{array}$ & $\begin{array}{c}\Delta \mathrm{V}, \\
\text { Venus } \\
(\mathrm{km} / \mathrm{s})\end{array}$ & $\begin{array}{c}\text { Mercury } \\
\text { arrival date } \\
\text { (J) }\end{array}$ & $\begin{array}{c}\text { Mercury } \\
\text { arrival } \Delta \mathrm{V} \\
(\mathrm{km} / \mathrm{s})\end{array}$ & $\begin{array}{c}\text { Stay time } \\
\text { (days) }\end{array}$ & $\begin{array}{c}\text { Mercury } \\
\text { departure } \Delta \mathrm{V} \\
(\mathrm{km} / \mathrm{s})\end{array}$ & $\begin{array}{c}\text { Mission } \\
\text { duration } \\
\text { (days) }\end{array}$ \\
\hline 1980 & 2444336 & 4.3 & 2444412 & 0.9 & 2444460 & 6.4 & 174 & 6.2 & 398 \\
\hline 1981 & 4716 & 8.9 & ----------- & --- & 4801 & 7.6 & 183 & 6.5 & 383 \\
\hline 1982 & 5000 & 4.2 & 5168 & --- & 5305 & 8.6 & 28 & 7.0 & 463 \\
\hline 1983 & 5484 & 4.8 & 5569 & --- & 5628 & 9.4 & 56 & 7.4 & 350 \\
\hline 1984 & 5828 & 8.1 & ----------- & --- & 5958 & 6.3 & 76 & 7.8 & 371 \\
\hline 1985 & 6196 & 7.0 & ------------ & --- & 6306 & 6.3 & 180 & 6.4 & 365 \\
\hline 1986 & 6562 & 6.7 & ----------- & --- & 6657 & 6.3 & 177 & 6.2 & 362 \\
\hline 1987 & 6918 & 6.9 & ----------- & --- & 7003 & 6.9 & 181 & 6.4 & 371 \\
\hline 1988 & 7330 & 5.6 & 7519 & 0.9 & 7630 & 4.7 & 18 & 9.7 & 383 \\
\hline 1989 & 7680 & 6.3 & 7865 & --- & 7922 & 8.3 & 72 & 8.7 & 379 \\
\hline 1990 & 8022 & 8.6 & ----------- & --- & 8157 & 6.4 & 77 & 7.6 & 367 \\
\hline 1991 & 8356 & 7.6 & ----------- & --- & 8506 & 6.3 & 182 & 6.8 & 372 \\
\hline 1992 & 8752 & 6.8 & ---------- & --- & 8857 & 6.1 & 179 & 6.3 & 364 \\
\hline 1993 & 9116 & 6.8 & --------- & --- & 9206 & 6.4 & 178 & 6.2 & 368 \\
\hline 1991 & 9650 & 4.2 & 9824 & --- & 9940 & 7.6 & 143 & 7.0 & 563 \\
\hline 1995 & 9812 & 6.7 & --------- & --- & 9897 & 8.9 & 186 & 7.0 & 401 \\
\hline 1996 & 2450180 & 4.5 & 2450305 & 3.0 & 2450390 & 6.8 & 44 & 7.4 & 404 \\
\hline 1997 & 810 & 4.0 & 976 & --- & 1100 & 7.9 & 136 & 6.4 & 421 \\
\hline 1998 & 946 & 7.0 & ----------- & --- & 1056 & 6.5 & 180 & 6.4 & 365 \\
\hline 1999 & 1312 & 6.6 & - - & --- & 1407 & 6.3 & 177 & 6.2 & 362 \\
\hline
\end{tabular}




\section{References}

1. Ehricke, K.A., "Lunar industrialization and settlement - Birth of poly-global civilization," Lunar Bases and Space Activities of the 21st Century Conference, Houston, TX, Lunar and Planetary Institute, 1985, p. 827-855.

2. Ehricke, K.A., "Harenodynamic cooling - The use of lunar sand as cooling medium," Acta Astronautica, Vol. 11, June 1984, p. 319-325.

3. Ehricke, K.A., "Profitability of manufacturing in space in view of lunar industrial development and geo-socio-economic benefits," Manufacturing in space; Proceedings of the Winter Annual Meeting, Boston, MA, Nov. 13-18, 1983, American Society of Mechanical Engineers, 1983, p. 183-198.

4. Ehricke, K.A., "A socio-economic evaluation of the lunar environment and resources. III Selenospheric economics and cislunar/terrestrial market analysis," IAF Paper 82-235, $33^{\text {rd }}$ International Astronautical Federation, International Astronautical Congress, Paris, France, Sept. 27Oct. 2, 1982, 25 p.

5. Ehricke, K.A., "A socio-economic evaluation of the lunar environment and resources. II - Energy for the selenosphere," IAF Paper 79-A-16, International Astronautical Federation, International Astronautical Congress, 30th, Munich, West Germany, Sept. 17-22, 1979, p. 25.

6. Ehricke, K.A., A socio-economic evaluation of the lunar environment and resources: I. Principles and overall system strategy," Acta Astronautica, Vol. 8, Issues 11-12, Nov-Dec 1981, pp. 1389-1405.

7. Ehricke, K., "Lunar industries and their value for the human environment on Earth," Acta Astronautica, 1974. Vol. 1, pp. 585-622.

8. Ehricke, K., "Further analyses of the slide lander and of drop delivery systems for improved lunar surface access," Acta Astronautica Vol. 10, No. 9, pp. 629 to 650, 1983.

9. Ehricke, K.A., "Economy of large launch vehicles including orbital labor cost," AIAA 1963-277.

10. Ehricke, K., "A comparison of propellants and working fluids for rocket propulsion," American Rocket Society (ARS) Journal, September-October 1953, Vol. 23, No. 5, pp. 287-300.

\section{MESSENGER at Mercury}

11. Lawrence, D.J., et al., "Evidence for Water Ice Near Mercury's North Pole from MESSENGER Neutron Spectrometer Measurements." Science 339, 292 (2013).

12. Chabot, N.L., Ernst, C.M., Denevi, B.W., Nair, H., Murchie, S.L., Blewett, D.T., Head, J.W., Harmon, J.K., and Solomon, S.C., "Imaging Inside Mercury's Permanently Shadowed Craters - First Images From Messenger," Paper 1693, 44th Lunar and Planetary Science Conference (2013).

13. MESSENGER Planetary Conference Multimedia Page - David A. Paige, MESSENGER Participating Scientist, University of California, Los Angeles, CA. http://messenger. jhuapl. edu/news room/presscon12 multi.html with: David A. Paige, et al., "Thermal Stability of Volatiles in the North Polar Region of Mercury," Science, January 18, 2013: Vol. 339, No. 6117, pp. 300-303.

\section{Cassini at Saturn}

14. Tobie, J.I., Lunine, J., Monteux, O., Mousis and Nimmo, F., "The Origin and Evolution of Titan," in Titan: Interior, Surface, Atmosphere and Space Environment, Muller-Wodarg, Griffith, Lellouch and Cravens, eds., Cambridge Univ Press, pp. 24-50, 2012. http://www.es.ucsc.edu/ fnimmo/website/Tobie Titan.pdf.

15. Spencer, J.R. and Nimmo, F., "Enceladus: An active ice world in the Saturn System," Annual Review of Earth and Planetary Sciences 41, 693-717, 2013.

\section{Ceres}

16. Rambaux, N., Castillo-Rogez, Dehant, J.V. and Kuchynka, P., "Constraining Ceres' interior from its Rotational Motion," Astronomy \& Astrophysics, manuscript no. Ceres 'Rambauxetal 11 ESO 2011, July 12, 2011, arXiv:1107.2051v1 [astro-ph.SR] 11 Jul 2011. 


\section{Mercury mission design}

17. Manning, L. "Comparison of Several Trajectory Modes for Manned and Unmanned Missions to Mercury 1980-2000," AIAA 67-28, 1967.

18. Marx, G., "Model study of fuel requirements for fast interplanetary flights using advanced nuclear propulsion systems and refueling at destination," Thesis, Technical University of Berlin (West Germany), In German, May 9, 1967.

19. Ehricke, K., "Study of Interplanetary Missions to Mercury Through Saturn With Emphasis on Manned Missions to Venus and Mars 1973/82 Involving Capture," Engineering Problems of Manned Interplanetary Exploration, 1963, AIAA 1963-1514.

20. Ehricke, K., "Perspective and Systems Engineering of Manned Planetary Flight," AAS 70-037, 1970. In: Space Shuttles and Interplanetary Flight, Vol. 28, Advances in Astronautical Sciences, 1970.

21. Palaszewski, B., "Metallized Propellants for the Human Exploration of Mars," NASA Lewis Research Center, NASA TP-3062, presented at the Case For Mars IV Conference, Boulder, CO, June 4-8 1990. Also in the AIAA Journal of Propulsion and Power, Vol. 8, No. 6, Nov.-Dec. 1992, pp. 1192-1199

22. Bensky, M., "Propulsion requirements for soft landing in extraterrestrial environments," Rocketdyne, NAS7-124, NASA CR-55088, Feb. 1963.

\section{Atmospheric mining in the outer solar system (AMOSS)}

23. Palaszewski, B., "Atmospheric Mining in the Outer Solar System: Resource Capturing, Storage, and Utilization," AIAA 2012-3742, July 2012.

24. Palaszewski, B., "Atmospheric Mining in the Outer Solar System: Issues and Challenges for Mining Vehicle Propulsion," AIAA 2011-6041, August 2011.

\section{Nuclear processing:}

25. Looper, M., "Radiation environment near the lunar surface CRaTER observations and Geant4 simulations," Space Weather, Vol. 11, pp. 142-152, 2013.

26. Cohen, G.D.; Sand, F.M., "Water Resource Applications, Underground Storage of Natural Gas, and Waste Disposal Using Underground Nuclear Explosions," Mathematica, Inc., Princeton, NJ, 31 Aug 1967: http://www.dtic.mil/get-tr-doc/pdf?AD=ADA395557.

27. Morrey, Jr, C.B.; Pinney, E.; Stoneham, R.G.; Chambre, P.L.; Lakness, R.M. "Underground Explosion Theory," University of Berkeley, CA, Apr 1952: http://www.dtic.mil/get-trdoc/pdf?AD $=$ AD0608885.

28. Sachs, D.C.; Swift, L.M., "Underground Explosion Effects," Stanford Research Inst., Menlo Park, CA, 03 Mar 1958: http://www.dtic.mil/get-tr-doc/pdf?AD=AD0617181 .

29. Brode, H.L., "Nuclear Explosions in Cavities," Rand Corp., Santa Monica, CA, Nov 1965.

30. Brode, H.L., "More Nuclear Explosions in Cavities," Rand Corp., Santa Monica, CA, Jun 1968.

31. Hoffman, G.A., "Thermoelectric Powerplants Utilizing Contained Nuclear Explosions," Rand Corp., Santa Monica, CA, 18 Feb 1960.

32. Gruber, S., "Charged Particle Beam-Plasma Interactions for Thermonuclear Power Generation," Final report, Case Western Reserve Univ., Cleveland, OH, Dept. of Electrical Engineering and Applied Physics, Jun 1974.

33. Wong, H.V.; Kotschenreuther, M.T.; Breizman, B.N.; Van Dam, J.W.; Hazeltine, Richard D., "Assessment of Compact Low Neutron Fusion Reactor Concepts," Final report, 15 Jun 1999-30 Nov 2000, Texas Univ. at Austin Inst. For Fusion Studies, 16 Feb 2000: http://www.dtic.mil/get-trdoc/pdf?AD=ADA387427.

34. Palaszewski, B., "Lunar Missions Using Advanced Chemical Propulsion: System Design Issues," NASA Lewis Research Center, NASA TP-3065, AIAA 90-2341, presented at the 26th AIAA/ASME/SAE Joint Propulsion Conference, Orlando, FL, July, 1990, also in AIAA Journal of Spacecraft and Rockets, Vol. 31, No. 3, May-June 1994, pp. 458-465. 


\section{Nuclear pulse propulsion}

35. Ehricke, K.A., "Interplanetary maneuvers in manned helionautical missions," 1965, AIAA 1965-695.

36. Ehricke, K.A., "Solar Transportation," Presented to the 4th Goddard Memorial Symposium, AM. Astronautical Soc., Washington, D.C., 15-16 Mar. 1966.

37. "A Grand Vision of Man's Role in Colonizing the Universe" by Oyang Teng, LaRouche Youth Movement (book review), Marsha Freeman, "Krafft Ehricke's Moon: The Extraterrestrial Imperative," Technology Editor of Executive Intelligence Review, 2009.

http://www.21stcenturysciencetech.com/Articles_2009/Summer-2009/Extraterrestrial_Imperative.pdf

38. Schmidt, G.R., Bonometti, J.A., and Irvine, C.A., "Project Orion and Future Prospects for Nuclear Pulse Propulsion,” Journal of Propulsion and Power, Vol. 18, No. 3, May-June 2002. 


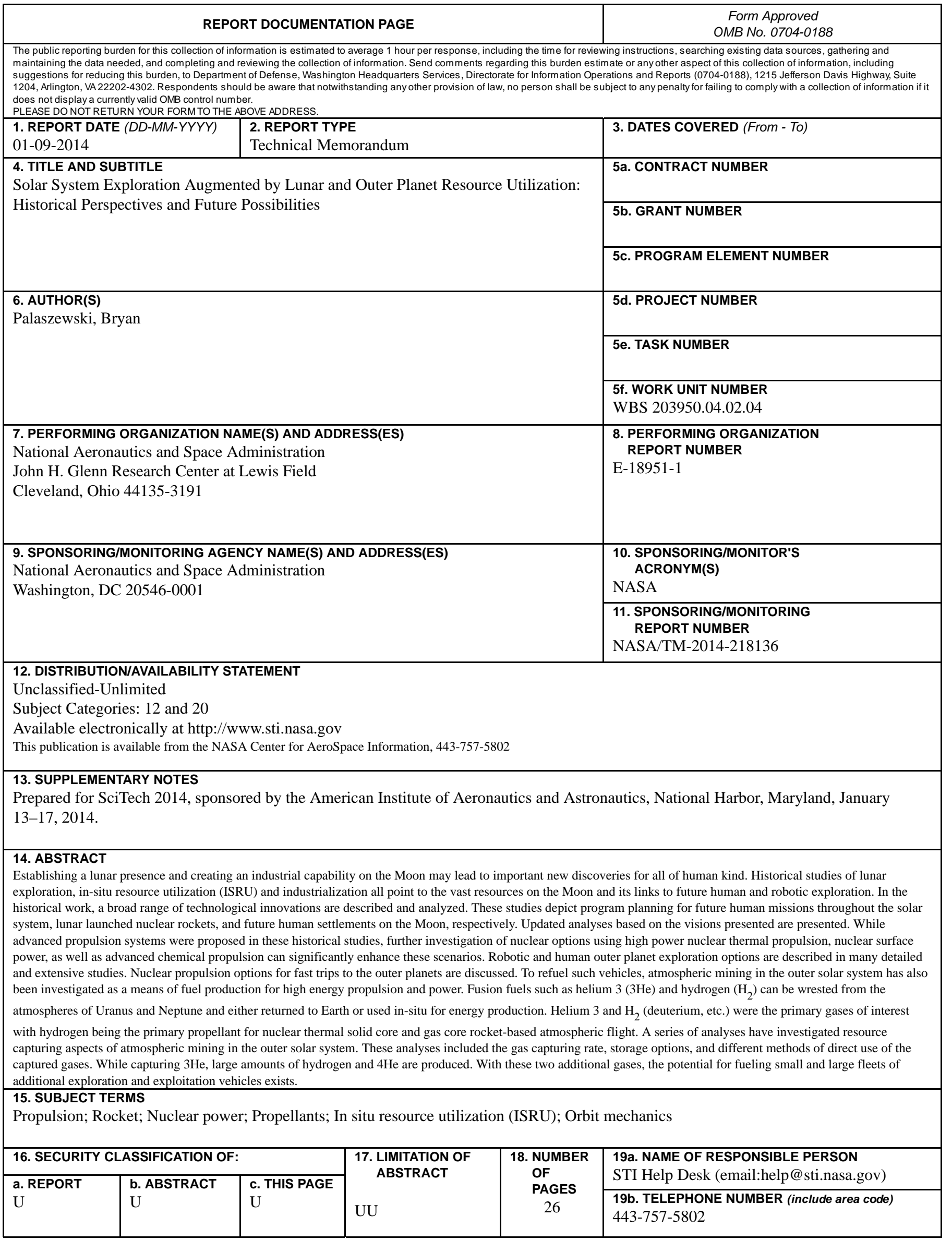



